Marquette University

e-Publications@Marquette

Clinical Lab Sciences Faculty Research and

Publications

Clinical Lab Sciences, Department of

9-2017

\title{
Point of Care Diagnosis of Multiple Schistosome Parasites: Species-specific DNA Detection in Urine by Loop-mediated Isothermal Amplification (LAMP)
}

\author{
Nilanjan Lodh \\ Marquette University, nilanjan.lodh@marquette.edu \\ Kei Mikita \\ Keio University School of Medicine \\ Kwabena M. Bosompem \\ Noguchi Memorial Institute for Medical Research \\ William K. Anyan \\ Noguchi Memorial Institute for Medical Research \\ Joseph K. Quartey \\ Noguchi Memorial Institute for Medical Research
}

See next page for additional authors

Follow this and additional works at: https://epublications.marquette.edu/clinical_lab_fac

Part of the Laboratory and Basic Science Research Commons

\section{Recommended Citation}

Lodh, Nilanjan; Mikita, Kei; Bosompem, Kwabena M.; Anyan, William K.; Quartey, Joseph K.; Otchere, Joseph; and Shiff, Clive J., "Point of Care Diagnosis of Multiple Schistosome Parasites: Species-specific DNA Detection in Urine by Loop-mediated Isothermal Amplification (LAMP)" (2017). Clinical Lab Sciences Faculty Research and Publications. 39.

https://epublications.marquette.edu/clinical_lab_fac/39 


\section{Authors}

Nilanjan Lodh, Kei Mikita, Kwabena M. Bosompem, William K. Anyan, Joseph K. Quartey, Joseph Otchere, and Clive J. Shiff

This article is available at e-Publications@Marquette: https://epublications.marquette.edu/clinical_lab_fac/39 
Marquette University

e-Publications@Marquette

\section{Clinical Laboratory Science Faculty Research and Publications/College of Health Sciences}

This paper is NOT THE PUBLISHED VERSION; but the author's final, peer-reviewed manuscript. The published version may be accessed by following the link in th citation below.

Acta Tropica, Vol. 173 (September 2017): 125-129. DOI. This article is (C) Elsevier and permission has been granted for this version to appear in e-Publications@Marquette. Elsevier does not grant permission for this article to be further copied/distributed or hosted elsewhere without the express permission from Elsevier.

\section{Point of Care Diagnosis of Multiple Schistosome Parasites: Species-Specific DNA Detection in Urine by Loop-Mediated Isothermal Amplification (LAMP)}

Nilanjan Lodh

Marquette University, College of Health Sciences, Department of Clinical Laboratory Science, Milwaukee, WI

Kei Mikita

Department of Infectious Diseases, Keio University School of Medicine, 35 Shinanomachi, Shinjuku-ku, Tokyo 160-8582, Japan

Kwabena M. Bosompem

Parasitology Department, Noguchi Memorial Institute for Medical Research (NMIMR), Legon, Accra, Ghana 
William K. Anyan

Parasitology Department, Noguchi Memorial Institute for Medical Research (NMIMR), Legon, Accra, Ghana

Joseph K. Quartey

Parasitology Department, Noguchi Memorial Institute for Medical Research (NMIMR), Legon, Accra, Ghana

\section{Joseph Otchere}

Parasitology Department, Noguchi Memorial Institute for Medical Research (NMIMR), Legon, Accra, Ghana

\section{Clive J. Shiff}

Department of Molecular Microbiology and Immunology, Johns Hopkins Bloomberg School of Public Health, Baltimore, MD

\section{Abstract}

Schistosomes are easily transmitted and high chance of repeat infection, so if control strategies based on targeted mass drug administration (MDA) are to succeed it is essential to have a test that is sensitive, accurate and simple to use. It is known and regularly demonstrated that praziquantel does not always eliminate an infection so in spite of the successes of control programs a residual of the reservoir survives to re-infect snails. The issue of diagnostic sensitivity becomes more critical in the assessment of program effectiveness. While serology, such as antigen capture tests might improve sensitivity, it has been shown that the presence of species-specific DNA fragments will indicate, most effectively, the presence of active parasites. Polymerase chain reaction (PCR) can amplify and detect DNA from urine residuecaptured on Whatman No. 3 filter paper that is dried after filtration. Previously we have detected S. mansoni and S. haematobium parasite-specific small repeat DNA fragment from filtered urine on filter paper by PCR. In the current study, we assessed the efficacy of detection of 86 urine samples for either or both schistosome parasites by PCR and loop-mediated isothermal amplification (LAMP) that were collected from a low to moderate transmission area in Ghana. Two different DNA extraction methods, standard extraction kit and field usable LAMP-PURE kit were also evaluated by PCR and LAMP amplification. With S. haematobium LAMP amplification for both extractions showed similar sensitivity and specificity when compared with PCR amplification (100\%) verified by gel electrophoresis. For $S$. mansoni sensitivity was highest for LAMP amplification (100\%) for standard extraction than PCR and LAMP with LAMP-PURE (99\% and 94\%). The LAMP-PURE extraction produced false negatives, which require further investigation for this field usable extraction kit. Overall high positive and negative predictive values $(90 \%-$ $100 \%$ ) for both species demonstrated a highly robust approach. The LAMP approach is close to point of care use and equally sensitive and specific to detection of species-specific DNA by PCR. LAMP can be an effective means to detect low intensity infection due to its simplicity and minimal DNA extraction requirement. This will enhance the effectiveness of surveillance and MDA control programs of schistosomiasis.

\section{Keywords}

Schistosomiasis, Urine, Repeat DNA, LAMP-PURE, PCR, LAMP

\section{Introduction}

Point of care diagnosis is a priority for strategies that rely on mass drug administration (MDA) for the control of many of the neglected tropical diseases(NTDs). As these strategies are applied and evaluated it is clear that the use of signs such as hematuria for urinary schistosomiasis or examination of stool smears such as the Kato-Katz 
(KK) test are unsatisfactory as diagnostics because of the lack of sensitivity (Lodh et al., 2013). Currently a point of care test for Schistosoma mansoni, the circulating cathodic antigen (CCA) test is in use, but it is similar in sensitivity as the KK smear in detecting $S$. mansoni and quite inadequate to detect $S$. haematobium infection (Stothard et al., 2006). Recently, however, it has been shown at least with schistosomes, that fragments of somatic DNA from both S. haematobiumand S. mansoni are detectable in urine (Ibironke et al., 2011), and can be extracted from filter paper through which a urine specimen was filtered and dried and thus avoids the collection and handling of stool specimens (Lodh et al., 2014). Although collecting and examining specimens has been greatly improved by filtration of urine in the field, and examination in a central laboratory, there still remains the need for thermocycler and electrophoresis equipment for the examination. These procedures can be replaced in the field by the loop-mediated isothermal amplification (LAMP) technology (Abbasi et al., 2010).

Detection of parasite species-specific DNA in urine indicates the presence of the actual parasite even when eggs or antigens are not always detectable, and schistosome DNA in urine has been shown to clear from infected people by two weeks after praziquantel treatment (Ibironke et al., 2012). In a carefully controlled study from Zambia, Lodh et al. (2013) showed that detecting S. mansoni species-specific DNA fragment in the urine precipitate, there was a 30\% disparity between CCA and PCR test. In China, (Xu et al., 2014) showed a six-fold difference between the KK smear (performed nine times per sample) and Schistosoma japonicum specific DNA detection from serum. Clearly it is important to add parasite species-specific DNA detection to the diagnostic repertoire and keep the technology as close to the point of care as possible (Shiff, 2014). The LAMP procedure commonly is made up from supplies obtainable from scientific vendors. It is highly specific as it uses four sets of primers to amplify six target regions of the DNA (Notomi et al., 2000). It also amplifies DNA fragments independent of the standard thermocycler and electrophoresis and can easily be adapted for clinical trials. The procedure depends on extraction and purification of the target DNA. This can be done by use of the standard DNA extraction kit (such as,QIAmpDNA Blood mini kit), or by other means of purification. The Eiken Chemical Company, Japan have produced a LAMP-PURE (Procedure for Ultra Rapid Extraction) kit, which incorporates a proprietary method for DNA extraction and purification in order to improve the sensitivity of the amplification process. In this work, we compared PCR amplification of DNA extracted and purified with QIAmpDNA Blood Mini kit against LAMP amplification of DNA extracted and purified with QIAmp and LAMPPURE to determine whether there was any advantage in diagnostic accuracy from 86 filtered urine specimens collected from a community in southern Ghana. The objective of this study was to compare the efficacy of two methods of extracting DNA from urine deposit on coarse filter paper (Whatman No 3.) dried after filtration and stored at room temperature (Ibironke et al., 2011) and their effect on two different types of amplification.

\section{Materials and methods}

\subsection{Study design and population}

The study location and population had been described in detail in previous publication (Lodh et al., 2014). Briefly, the study was carried out at Tomefa, a district of the greater Accra region in Ghana. Colleagues of the Noguchi Memorial Institute for Medical Research (NMIMR) chose this area because of the presence of both $S$. mansoni and S. haematobium and an ongoing study that focused on intestinal schistosomiasis for NMIMR. Stool specimens for $S$. mansoni were examined using the KK method, but there was no urine examination for $S$. haematobium. For this study, urine samples were collected from 86 participants between 5 and 23 years of age specifically for DNA detection. Approval for the diagnostic research was provided by NMIMR (IRB: 043/12-13). Written study consent was collected from parents or guardians in case of minors and from individuals in case of 18 years or older. Participants found infected parasitologically were treated by praziquantel by NMIMR and local health centers. 
Urine samples (approximately 40-50 mL) were collected between 10:00 am and 2:00 pm and were evaluated for color, $\mathrm{pH}$, and specific gravity and for presence of protein, glucose bilirubin and hematuria with Hemastix (Bayer, Elkhart, IN). After physiological assessment, approximately $50 \mathrm{~mL}$ whole urine was filtered through Whatman No. 3 filter paper (Whatman International, Maidstone, England), then dried under a fly-proof net and individually packed in Ziploc bags with desiccant. Filter papers without any personal information and only with number associated with specimen along with age, sex, physiological and diagnostic information were brought back to Johns Hopkins School of Public Health, Baltimore, Maryland for molecular diagnosis. DNA was extracted from urine sediment captured on filter paper by QIAmpDNA Blood Mini Kit (Qiagen, MD) and LAMP PURE kit (Eiken Chemical Co., Ltd, Japan). DNA extracted by Qiagen kit was evaluated by both PCR and LAMP. LAMP PURE kit extracted DNA was evaluated only by LAMP.

\subsection{DNA extraction from urine by Qiagen and LAMP PURE kit}

Each filter paper was folded to form a cone to drain the urine. DNA was extracted from marked inner quadrant at the base of filter paper by QIAmpDNA Blood Mini Kit (Qiagen, MD, USA). From each quadrant 15 pieces of $\sim 1 \mathrm{~mm}$ diameter paper disc was punched off by a regular paper punch. After every use, the paper punch and scissor was cleaned by $10 \%$ bleach solution and distilled water to avoid any contamination. All 15 paper discs for each sample were placed in $1.5 \mathrm{~mL}$ Eppendorf tube with $600 \mu \mathrm{L}$ nuclease-free water and heated at $95^{\circ} \mathrm{C}$ for $10 \mathrm{~min}$ and then kept on a rotor at room temperature $\left(22-25^{\circ} \mathrm{C}\right)$ for $16-18 \mathrm{~h}$. The next day water solution was transferred to a Qiagen QIAmp $2 \mathrm{~mL}$ column tube and DNA was extracted by following manufacturer's protocol.

The adjacent quadrant was used to extract DNA by LAMP-PURE kit. The PURE kit was consisted of a series of extraction and purifying steps. Step 1: An aliquot of sample (water extract as described above) was heated at $90^{\circ} \mathrm{C}$ for $10 \mathrm{~min}$ using a water bath to lyse any cellular material. This was added to the manufacturers DNA extraction solution, mixed by inversion and incubated. Step 2: The sample was then treated with adsorbent ingredient to remove inhibitory materials contained in the sample and to neutralize the solution without any loss of the target DNA.

DNA concentration was measured using the NanoDrop ND-1000 spectrophotometer (NanoDrop Technologies, USA). Qiagen-kit-extracted DNA concentration was ranged from 1 to $10 \mathrm{ng} / \mu \mathrm{L}$. PURE-kit-extracted DNA concentration was ranged from 50 to $1200 \mathrm{ng} / \mu \mathrm{L}$. Therefore, PURE-kit-extracted DNA was diluted at 1:10 ratio as DNA concentration was too high for amplification.

\subsection{PCR amplification for S. mansoni and S. haematobium}

PCR amplification was carried out in $10 \mu \mathrm{L}$ volume with positive and negative controls. For S. mansoni, KK positives were used as positive control and for S. haematobium, hematuria and urine filtration positives were used as positive control. Water was used as negative control for both parasite species. For PCR amplification, the reaction volume consisted of $5 \mu \mathrm{L}$ of PCR Master Mix, $2 X$ (Promega, Madison, WI, USA), $0.5 \mu \mathrm{L}(10 \mu \mathrm{M})$ of each amplification primers, $1.5-2 \mu \mathrm{L}$ of $25 \mathrm{mM} \mathrm{MgCl}_{2}, 2 \mu \mathrm{L}$ of DNA (concentration: 4-6 $\mathrm{ng} / \mu \mathrm{L}$ ) and rest nuclease-freewater. The amplification profile for S. mansoni was initial denaturation at $95{ }^{\circ} \mathrm{C}$ for $10 \mathrm{~min}$ and 35 cycles at $95{ }^{\circ} \mathrm{C}$ for $30 \mathrm{~s}, 60^{\circ} \mathrm{C}$ for $90 \mathrm{~s}, 72{ }^{\circ} \mathrm{C}$ for $30 \mathrm{~s}$ and a final extension at $72{ }^{\circ} \mathrm{C}$ for $5 \mathrm{~min}$. For S. haematobium the denaturing step was at $95{ }^{\circ} \mathrm{C}$ for $10 \mathrm{~min}$, followed by 33 cycles of $95{ }^{\circ} \mathrm{C}$ for $30 \mathrm{~s}, 53^{\circ} \mathrm{C}$ for $90 \mathrm{~s}$, and $72{ }^{\circ} \mathrm{C}$ for $1 \mathrm{~min}$, followed by a final extension step at $60^{\circ} \mathrm{C}$ for $5 \mathrm{~min}$. To confirm amplification and correct ampliconsize, PCR products were visualized in $2 \%$ agarose gel stained with ethidium bromide $(10 \mathrm{mg} / \mu \mathrm{L}$ ) with $50 \mathrm{bp}$ DNA marker (New England BioLabs Inc., Ipswich, MA, USA).

Eighty-six urine samples were investigated by PCR for both schistosome species DNA obtained from Qiagen miniprep. For S. mansoni, PCR was carried out by amplifying 110 bp fragment from a highly repeated $121 \mathrm{bp}$ region of S. mansonidescribed by Hamburger (Hamburger et al., 1991). Primers for PCR amplification were 
described by Pontes et al. (Pontes et al., 2002). For S. haematobium 121 bp Dra Irepeat fragment was amplified by primers previously designed by Hamburger et al. (Hamburger et al., 2001). In case of both schistosome species the repeat fragments comprise of $12-16 \%$ of each parasite genome ( 600,000 copies per cell) occur in different region of genomes of these two schistosome parasites.

\subsection{LAMP amplification for S. mansoni and S. haematobium}

The LAMP ready-to-use buffer mix was prepared to do the LAMP amplification and was performed on two separate DNA templates, one (labeled LAMP) was obtained with Qiagen Miniprep kit and the second (labeled LAMP-PURE) was obtained with LAMP-PURE extraction and purification kit. The following procedures were carried out. The buffer mix was composed of $2 X$ concentration of the following reagents: 10X LAMP buffer (Eiken Chemical Co., Ltd, Japan), 5 M Betaine (Sigma, St. Louis, MO), 10 mM dNTPs (Promega, Madison, WI). Four $\mu \mathrm{L}$ of ready mix buffer was used for $10 \mu \mathrm{L}$ LAMP reaction mix. Other than ready mix the reaction mix contained $0.5 \mu \mathrm{L}$ of LAMP primers ( 5 pmoles of $\mathrm{F} 3$ and B3 and 40 pmoles of FIP and BIP), $1 \mu \mathrm{L}$ of Bst DNA polymerase (Lucigen, Middleton, WI), $2 \mu \mathrm{L}$ of extracted DNA and $0.5 \mu \mathrm{L}$ nuclease free water. LAMP amplification was for $2 \mathrm{~h}$ at $63^{\circ} \mathrm{C}$ with inactivation for $5 \mathrm{~min}$ at $80^{\circ} \mathrm{C}$. Detection of LAMP products were performed by using SYBR Green I stain (Life Technologies, Grand Island, NY) by adding $1 \mu \mathrm{L}$ (1:20 dilution). To confirm correct amplification, LAMP products were visualized in $2 \%$ agarose gel stained with ethidium bromide $(10 \mathrm{mg} / \mu \mathrm{L})$ and run with $50 \mathrm{bp}$ ladder (New England BioLabs Inc., Ipswich, MA). Details of primers were used, including the internal species specific F3 and B3 as well as the loop FIB and BIP primers for each schistosome species were given in Table 1.

Table 1. Primer sets used for species-specific DNA amplification of Schistosoma mansoni and S. haematobium by LAMP and PCR methods .

\begin{tabular}{|c|c|c|c|c|}
\hline $\begin{array}{l}\text { Schistosome } \\
\text { parasite }\end{array}$ & $\begin{array}{l}\text { Amplification } \\
\text { type }\end{array}$ & $\begin{array}{l}\text { Oligonucleotide } \\
\text { name }\end{array}$ & Oligonucleotide sequence & Reference \\
\hline \multirow[t]{6}{*}{$\begin{array}{l}\text { Schistosoma } \\
\text { mansoni }\end{array}$} & LAMP & F3 & 5' GAT CTG AAT CCG ACC AAC CG 3' & $\frac{\text { Hamburger et }}{\text { al., } 2013}$ \\
\hline & & B3 & $5^{\prime}$ AAC GCC CAC GCT CTC GCA 3' & \\
\hline & & FIP & $\begin{array}{l}5^{\prime} \text { AAA TCC GTC CAG TGG TTT TTT TGA } \\
\text { AAA TCG TTG TAT CTC CG 3' }\end{array}$ & \\
\hline & & BIP & $\begin{array}{l}5^{\prime} \text { CCG AAA CCA CTG GAC GGA TTT TTA } \\
\text { TTT TTA ATC TAA AAC AAA CAT C } 3^{\prime}\end{array}$ & \\
\hline & PCR & SmPF & 5' GAT CTG AAT CCG ACC AAC CG 3' & $\begin{array}{l}\text { Pontes et al., } \\
2002\end{array}$ \\
\hline & & SmPR & $5^{\prime}$ ATA TTA ACG CCC ACG CTC TC $3^{\prime}$ & \\
\hline \multirow[t]{7}{*}{$\begin{array}{l}\text { Schistosoma } \\
\text { haematobium }\end{array}$} & LAMP & F3 & 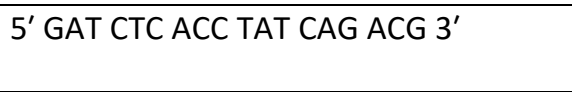 & $\begin{array}{l}\text { Hamburger et } \\
\text { al., } 2013\end{array}$ \\
\hline & & B3 & $55^{\prime}$ GTC ACC AAT AAT ATG AAA C 3' & \\
\hline & & FIP & $\begin{array}{l}\text { 5' CCA ACA ATT TTA AAT TTT ATC AGA } \\
\text { CGA AAC AAA GAA AAT 3' }\end{array}$ & \\
\hline & & BIP & $\begin{array}{l}\text { 5' GGT CGT ATC GTT GTG AAA TTT TCA } \\
\text { CCA ATA ATA TGA AAC AAT 3' }\end{array}$ & \\
\hline & PCR & ShDra1F & $5^{\prime}$ TCA CAA CGA TAC GAC CAA C $3^{\prime}$ & $\begin{array}{l}\text { Hamburger et } \\
\text { al., } 2001\end{array}$ \\
\hline & & ShDra1R & 5' GAT CTC ACC TAT CAG ACG AAA C 3' & \\
\hline & & ShDra1R & $5^{\prime}$ TCA CAA CGA TAC GAC CAA C $3^{\prime}$ & 2001 \\
\hline
\end{tabular}

${ }^{a}$ LAMP = loop-mediated isothermal amplification; $P C R=$ polymerase chain reaction; $F 3=$ forward external primer; $\mathrm{B} 3$ = backwards external primer; FIP = forward internal primer; BIP = backwards internal primer. 


\subsection{Statistical analyses}

The analytical procedure was designed to compare two approaches of DNA amplification. Specificity and sensitivity of urine-based DNA detection for diagnosis of current schistosome infections had been evaluated (Lodh et al., 2014). Data generated in the study were evaluated quantitatively and qualitatively. Also, agreement statistics, Bowker's Symmetry (Anne and Sonja 2007) was calculated to determine the accuracy of the tests. Bowker's symmetry tested for lack of agreement between comparisons of two tests. Only numerical values ( $1=$ positive and $0=$ negative) were used for statistical analysis. Data for S. mansoni were represented as PCR_S. mansoni_QiaAmp kit, LAMP_S. mansoni_QiaAmp kit, LAMP_S. mansoni_PURE kit, and for S. haematobium were represented as PCR_S. haematobium_QiaAmp kit, LAMP_S. haematobium_QiaAmp kit and LAMP_S. haematobium_PURE kit.

In this study PCR + was regarded as true positive and PCR - was regarded as true negative. Positivity and negativity for LAMP amplification of Qiagen extracted DNA and PURE kit extracted DNA was determined based on the PCR outcomes. The sensitivity, specificity, positive predictive value (PPV), negative predictive value (NPV) was calculated using MedCalc 12.4.0 (MedCalc Software, Belgium). Agreement statistics, Bowker's Symmetry was calculated by JMP 9 (JMP ${ }^{\oplus}$ v9, SAS Institute Inc., Cary, North Carolina) to determine the agreement between PCR and LAMP diagnostic tests.

\subsection{Assessment of positive and negative cases}

The results were analyzed as follows:

- If KK+ then presence of infection confirmed for S. mansoni.

- If PCR+ or LAMP+ (S. haematobium primers) presence of infection for S. haematobium.

- If PCR+ or LAMP+ (S. mansoni primers) presence of infection for S. mansoni.

- If both products were amplified from one specimen then presence of dual S. mansoni and $S$. haematobium infection.

\section{Results}

\subsection{Evaluation of PCR and LAMP}

We found a large number of mixed S. mansoni/S. haematobium infections by both PCR and LAMP amplification (Table 2). There were 72/86 S. haematobium and 81/86 S. mansoni with LAMP assay, whereas $21 \%$ false negativity with the KK specimen exam. The LAMP-PURE for $S$. mansoni did not perform well as expected with this parasite, showing $6 \%$ false negative. In supplementary material, two by two tables are presented for comparison of the PCR and LAMP amplification methods and the two DNA extraction methods. Overall the detection of $S$. haematobium using LAMP method is similar for both extraction and only two specimens were missed by PCR amplified from Qiagen extracted DNA. The differences were not significant.

Table 2. Frequency of infected and uninfected people from Ghana for Schistosoma mansoni and $S$. haematobium evaluated by polymerase chain reaction (PCR) and loop mediated isothermal amplification (LAMP), where DNA was extracted by QiaAmp extraction kit and by LAMP-PURE kit.

\begin{tabular}{|l|l|l|l|l|l|}
\hline Diagnostic Test & $\begin{array}{l}\text { True Positive } \\
(\mathrm{TP})\end{array}$ & $\begin{array}{l}\text { False positive } \\
(\mathrm{FP})\end{array}$ & $\begin{array}{l}\text { True Negative } \\
(\mathrm{TN})\end{array}$ & $\begin{array}{l}\text { False Negative } \\
\text { (FN) }\end{array}$ & Total \\
\hline KK ${ }^{\text {a }}$ _S. mansoni & $57(66 \%)$ & 0 & $11(13 \%)$ & $18(21 \%)$ & 86 \\
\hline PCR_S. mansoni_QiaAmp kit & $74(86 \%)$ & 0 & $11(13 \%)$ & $1(1 \%)$ & 86 \\
\hline LAMP_S. mansoni_QiaAmp kit & $81(94 \%)$ & 0 & $5(6 \%)$ & 0 & 86 \\
\hline LAMP_S. mansoni_PURE kit & $76(88 \%)$ & 0 & $5(6 \%)$ & $5(6 \%)$ & 86 \\
\hline
\end{tabular}




\begin{tabular}{|l|l|l|l|l|l|}
\hline $\begin{array}{l}\text { PCR_S. haematobium_QiaAmp } \\
\text { kit }\end{array}$ & $70(81 \%)$ & 0 & $16(19 \%)$ & 0 & 86 \\
\hline $\begin{array}{l}\text { LAMP_S. } \\
\text { haematobium_QiaAmp kit }\end{array}$ & $72(84 \%)$ & 0 & $14(16 \%)$ & 0 & 86 \\
\hline $\begin{array}{l}\text { LAMP_S. haematobium_PURE } \\
\text { kit }\end{array}$ & $72(84 \%)$ & 0 & $14(16 \%)$ & 0 & 86 \\
\hline
\end{tabular}

${ }^{\mathrm{a} K K}=$ Kato-Katz test.

\subsection{Assessment of agreement statistics}

Agreement statistics was calculated by comparing two above-mentioned molecular methods for both $S$. mansoni and S. haematobium. Bowker's symmetry calculated the level of disagreement between tests in 2-way tables and the test decision was based on $X^{2}$ approximation of the distribution of the test statistic (Anne and Sonja, 2007). For S. mansoni, the Bowker Symmetry was significantly different from random $(P<0.05)$ for the comparison between LAMP_QiaAmp and PCR and in case of LAMP_QiaAmp and LAMP_PURE, indicating that test positives by LAMP_QiaAmp were highly unlikely to be the same with PCR and LAMP_PURE (Table 3). The test agreement was significantly correlated for PCR and LAMP_PURE (0.33; Table 4). For S. haematobium, the symmetry of disagreement was also significantly lower throughout for all comparisons ( 0 and 2$)$, which indicated that test positives by LAMP_QiaAmp are highly likely to be same with PCR and LAMP_PURE (Table 3).

Table 3. Estimation of Bowker symmetry index (Agreement Statistics) for two species-specific DNA amplification methods and two DNA extraction methods.

\begin{tabular}{|l|l|l|}
\hline \hline Diagnostic Test & Bowker's Symmetry test* & \\
\hline & Symmetry of Disagreement & P value $^{\Psi}$ \\
\hline PCR_S. mansoni_QiaAmp kit vs. LAMP_S. mansoni_QiaAmp kit & 7 & $0.0082^{*}$ \\
\hline PCR_S. mansoni_QiaAmp kit vs LAMP_S. mansoni_PURE kit & 0.33 & 0.5637 \\
\hline LAMP_S. mansoni_QiaAmp kit vs. LAMP_S. mansoni_PURE kit & 5 & $0.0253^{*}$ \\
\hline PCR_S. haematobium_QiaAmp kit vs. LAMP_S. haematobium_QiaAmp kit & 2 & 0.1573 \\
\hline PCR_S. haematobium_QiaAmp kit vs. LAMP_S. haematobium_PURE kit & 2 & 0.1573 \\
\hline LAMP_S. haematobium_QiaAmp kit vs. LAMP_S. haematobium_PURE kit & 0 & 1.0000 \\
\hline
\end{tabular}

*Bowker's Symmetry test $=$ this test checks for symmetry in 2-way tables and the test decision is based on

a $X^{2}$ approximation of the distribution of the test statistic.

$\psi=\alpha$ level was set at 0.05 .

$*$ Significant.

\section{Discussion}

In the current study, LAMP was used for integrated diagnosis of single or mixed schistosome infection by amplifying parasite species-specific DNA from urine samples. Recently our group successfully detected schistosome parasite-specific DNA by PCR amplification in S. haematobium (Ibironke et al., 2011) and S. mansoni(Lodh et al., 2013) individually and for both S. haematobium and S. mansoni (Lodh et al., 2014) from urine sediment captured on filter paper through filtration. In all cases, our approach showed high sensitivity and specificity with no cross-reactivity with other related helminthes. However, there is an added cost and technological limitation involved for employing PCR based DNA detection in the field (Hamburger et al., 1991). A simple molecular procedure adapted as a point of care diagnostic test to rural conditions is needed, and for this we used LAMP technology.

In Africa the two human species of schistosomes, S. mansoni and S. haematobium are often concurrent in the human population (Hotez and Fenwick, 2009). This sympatric distribution also raises the problem of accurate and specific diagnosis of asymptomatic cases. It is important to remember that such cases can still infect molluscan hosts and keep the transmission going. So these reservoirs of infection must be detected in order to 
eliminate the risk of human re-infection. Sensitivity of microscopic examination decreases in older people so that the relationship of each parasite with human morbidity is not evaluated (King and Dangerfield-Cha, 2008) and this will affect disease treatment and any control effort (Booth et al., 2004, Ernould et al., 1999). Differentiating between these species can be challenging, as it involves the examination of urine for egg or antigen by dipstick or by CCA and stool for egg detection. Logistically and technically such tasks are time consuming and as shown (Ibironke et al., 2011, Lodh et al., 2013) these procedures are inadequately sensitive and produce false negative results. Active schistosome infections are normally diagnosed by demonstrating parasite eggs in the excreta, however in chronic and low-intensity infections these eggs appear sporadically and are difficult to detect. This is extremely critical with intestinal schistosomiasis when the standard method, the KK technique uses only $50 \mathrm{mg}$ feces, some $1 / 10,000$ of a normal fecal mass. This is particularly important when mass chemotherapy programs are designed to reduce or eliminate foci of infection. For S. haematobium, the repeat DNA detection in urine is superior in sensitivity and specificity to antigen capture, hematuria or ELISA detection of antibody. WHO has drawn attention to the need for tests with high specificity but also improved sensitivity, which can be applicable in the field. We have demonstrated that it is possible to detect DNA specific to both schistosome parasites from a single source of urine, thus simplifying the collection and performance of tests that are more sensitive and more specific than the standard diagnostic tests (Enk et al., 2010). This will be a significant development in schistosome diagnosis, it would greatly increase the ease by which specimen collections are made and it will increase the accuracy of the diagnosis significantly as has been shown in our work with S. haematobium.

The success of control strategies requires a simple, easy-to-perform, sensitive and accurate diagnostic test. However, current diagnostics of all forms of schistosomiasis are insufficient to detect lowintensity asymptomatic and chronic infections. Detection of eggs and surface and/or secreted antigens is prone to missing low-grade infections (Stothard et al., 2006Krolewiecki et al., 2013), which comprise the majority of infections particularly adults with long-standing infections and juveniles who have been treated. As the control programs become more and more effective in reducing the parasite burden in the individual, the issue of diagnostic sensitivity will become more critical in the assessment of program effectiveness (Ibironke et al., 2011; Krolewiecki et al., 2013). That is why an accurate and sensitive point of care diagnostic test is needed.

LAMP has already been used for several major NTDs, notably for malaria (Hopkins et al., 2013, Polley et al., $\underline{2013}$ ), tuberculosis (Mitarai et al., 2011), toxoplasmosis(Mikita et al., 2013), leishmaniasis (Mikita et al., 2014) and for schistosome-infected-snails (Hamburger et al., 2013). LAMP is rapid and simple as the reaction can be done at a constant temperature with only one type of enzyme (Tomita et al., 2008). LAMP is highly specific as it uses four sets of primers to amplify six target regions of the DNA (Tomita et al., 2008). It also amplifies DNA fragments independent of the standard thermocycler and electrophoresis and can easily be adapted for clinical trials. By using LAMP simpler, rapid and specific schistosome DNA-based testing of urine can be employed in the field for rapid detection of human schistosome parasites. We show that isothermal amplification of schistosome species-specific DNA is an effective diagnostic procedure and is equal to PCR amplification for both species of schistosome.

\section{Acknowledgements}

We acknowledge National Defense College of Tokorozawa City, Japan for their kind donation of LAMP-PURE kits for this study. Financial support for LAMP, PCR and other molecular work came from the Department of Molecular Microbiology and Immunology of Johns Hopkins School of Public Health allocation. Dr. Jean M. Naples and Joseph Quartey did specimen collection and parasitological examination under supervision of Dr. Kwabena M. Bosompem at Noguchi Memorial Institute for Medical Research (NMIMR), Ghana.

Recommended articlesCiting articles (7) 


\section{References}

Abbasi et al., 2010 I. Abbasi, C.H. King, E.M. Muchiri, J. Hamburger Detection of Schistosoma mansoni and Schistosoma haematobium DNA by loop-mediated isothermal amplification: identification of infected snails from early prepatency Am. J. Trop. Med. Hyg., 83 (2010), pp. 427-432

Anne and Sonja, $2007 \mathrm{~K}$. Anne, K. Sonja Bowker's test for symmetry and modifications within the algebraic framework Comput. Stat. Data Anal., 51 (2007), pp. 4124-4142

Booth et al., 2004

M. Booth, B.J. Vennervald, A.E. Butterworth, H.C. Kariuki, C. Amaganga, G. Kimani, J.K. Mwatha, A. Otedo, J.H. O uma, D.W.Dunne Exposure to malaria affects the regression of hepatosplenomegaly after treatment for Schistosoma mansoni infection in Kenyan children BMC Med., 2 (2004), p. 36

Enk et al., 2010 M.J. Enk, E.S. Oliveira, N.B. Rodrigues A salting out and resin procedure for extracting Schistosoma mansoniDNA from human urine samples BMC Res. Notes, 3 (2010), p. 115

Ernould et al., 1999 J.C. Ernould, K. Ba, B. Sellin Increase of intestinal schistosomiasis after praziquantel treatment in a Schistosoma haematobium and Schistosoma mansoni mixed focus Acta Trop., 73 (1999), pp. $143-152$

Hamburger et al., 1991 J. Hamburger, T. Turetski, I. Kapeller, R.Deresiewicz Highly repeated short DNAsequences in the genome of Schistosoma mansoni recognized by a species-specific probe Mol. Biochem. Parasitol., 44 (1991), pp. 73-80

Hamburger et al., 2001 J. Hamburger, N. He, I. Abbasi, R.M. Ramzy, J.Jourdane, A. Ruppel Polymerase chain reaction assay based on a highly repeated sequence of Schistosoma haematobium: a potential tool for monitoring schistosome-infested water Am. J. Trop. Med. Hyg., 65 (2001), pp. 907-911

Hamburger et al., 2013

J. Hamburger, I. Abbasi, C. Kariuki, A. Wanjala, E.Mzungu, P. Mungai, E. Muchiri, C.H. King Evaluation of loopmediated isothermal amplification suitable for molecular monitoring of schistosome-infected snails in field laboratories Am. J. Trop. Med. Hyg., 88 (2013), pp. 344-351

Hopkins et al., 2013

H. Hopkins, I.J. Gonzalez, S.D. Polley, P. Angutoko, J.Ategeka, C. Asiimwe, B. Agaba, D.J. Kyabayinze, C.J. Sutherla nd, M.D.Perkins, D. Bell Highly sensitive detection of malaria parasitemia in a malaria-endemic setting: performance of a new loop-mediated isothermal amplification kit in a remote clinic in Uganda J. Infect. Dis., 208 (2013), pp. 645-652

Hotez and Fenwick, 2009 P.J. Hotez, A. Fenwick Schistosomiasis in Africa: an emerging tragedy in our new global health decade PLoS Negl. Trop. Dis., 3 (2009)

Ibironke et al., 2011 O.A. Ibironke, A.E. Phillips, A. Garba, S.M. Lamine, C.Shiff Diagnosis of Schistosoma haematobium by detection of specific DNA fragments from filtered urine samples Am. J. Trop. Med. Hyg., 84 (2011), pp. 998-1001

Ibironke et al., 2012 O. Ibironke, A. Koukounari, S. Asaolu, I. Moustaki, C.Shiff Validation of a new test for Schistosoma haematobium based on detection of Dra1 DNA fragments in urine: evaluation through latent class analysis PLoS Neg.Trop. Dis., 6 (2012), p. e1464

King and Dangerfield-Cha, 2008 C.H. King, M. Dangerfield-Cha The unacknowledged impact of chronic schistosomiasis Chron. Illness, 4 (2008), pp. 65-79 
Lodh et al., 2013 N. Lodh, J.C.L. Mwansa, M.M. Mutengo, C.J. Shiff Diagnosis of Schistosoma mansoni without the stool: comparison of three diagnostic tests to detect Schistosoma mansoni infection from filtered urine in Zambia Am. J. Trop. Med. Hyg., 89 (2013), pp. 46-50

Lodh et al., 2014 N. Lodh, J.M. Naples, K.M. Bosompem, J. Quartey, C.J.Shiff Detection of parasite-specific DNA in filtered urine effectively differentiates between single and mixed infections of Schistosoma mansoni and $S$. haematobium from endemic areas in Ghana PLoS One, 9 (2014), p. e91144

Mikita et al., 2013 K. Mikita, T. Maeda, T. Ono, Y. Miyahira, T. Asai, A.Kawana The utility of cerebrospinal fluid for the molecular diagnosis of toxoplasmic encephalitis Diag. Microbiol. Infect. Dis., 75 (2013), pp. 155-159

Mikita et al., 2014 K. Mikita, T. Maeda, S. Yoshikawa, T. Ono, Y. Miyahira, A.Kawana The direct boil-LAMP method: a simple and rapid diagnostic method for cutaneous leishmaniasis Parasitol. Int., 63 (2014), pp. 785789

Mitarai et al., 2011

S. Mitarai, M. Okumura, E. Toyota, T. Yoshiyama, A.Aono, A. Sejimo, Y. Azuma, K. Sugahara, T. Nagasawa, N. Nag ayama, A.Yamane, R. Yano, H. Kokuto, K. Morimoto, M. Ueyama, M. Kubota, R.Yi, H. Ogata, S. Kudoh, T. Mori Evaluation of a simple loop-mediated isothermal amplification test kit for the diagnosis of tuberculosis Int. J. Tuber. Lung Dis.: J. Int. Union Against Tuber. Lung Dis., 15(2011), pp. 1211-1217 (i)

Notomi et al., 2000 T. Notomi, H. Okayama, H. Masubuchi, T. Yonekawa, K.Watanabe, N. Amino, T. Hase Loopmediated isothermal amplification of DNA Nuc. Acids Res., 28 (2000) e63-e63

Polley et al., 2013

S.D. Polley, I.J. Gonzalez, D. Mohamed, R. Daly, K.Bowers, J. Watson, E. Mewse, M. Armstrong, C. Gray, M.D. Per kins, D.Bell, H. Kanda, N. Tomita, Y. Kubota, Y. Mori, P.L. Chiodini, C.J.Sutherland Clinical evaluation of a loopmediated amplification kit for diagnosis of imported malaria J. Infect. Dis., 208 (2013), pp. 637-644

Pontes et al., 2002 L.A. Pontes, E. Dias-Neto, A. Rabello Detection by polymerase chain reaction of Schistosoma mansoni DNA in human serum and feces Am. J. Trop. Med. Hyg., 66 (2002), pp. 157-162

Shiff, 2014 C. Shiff New diagnostics reform infectious parasite epidemiology Lancet Infect. Dis., 14 (2014), pp. 446-448

\section{Stothard et al., 2006}

J.R. Stothard, N.B. Kabatereine, E.M. Tukahebwa, F.Kazibwe, D. Rollinson, W. Mathieson, J.P. Webster, A. Fenwic $k$ Use of circulating cathodic antigen (CCA) dipsticks for detection of intestinal and urinary schistosomiasis Acta Trop., 97 (2006), pp. 219-228

Tomita et al., 2008 N. Tomita, Y. Mori, H. Kanda, T. Notomi Loop-mediated isothermal amplification (LAMP) of gene sequences and simple visual detection of products Nat. Protoc., 3 (2008), pp. 877-882

Xu et al., 2014 X. Xu, Y. Zhang, D. Lin, J. Zhang, J. Xu, F. Liu Y.-m. Hu, X.Qing, C. Xia, W. Pan Serodiagnosis of Schistosoma japonicum infection: genome-wide identification of a protein marker, and assessment of its diagnostic validity in a field study in China Lancet Infect. Dis., 14 (2014), pp. 489-497 


\section{Appendix A. Supplementary data}

The following is Supplementary data to this article:

\section{Supplementary material}

Quantitative analysis of two different diagnostic tests on 86 filtered urine sediments collected in Ghana where $0=$ negative and $1=$ positive.

A. S. mansoni

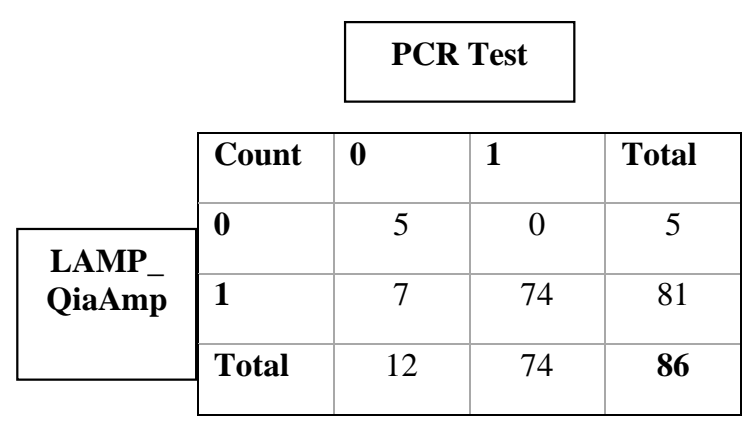

B. S. haematobium

\begin{tabular}{|l|l|l|l|r|}
\cline { 2 - 5 } & \multicolumn{3}{|c|}{ PCR Test } & \multicolumn{1}{c}{} \\
\cline { 2 - 5 } & Count & $\mathbf{0}$ & $\mathbf{1}$ & Total \\
\hline $\begin{array}{l}\text { LAMP_ } \\
\text { QiaAmp }\end{array}$ & $\mathbf{0}$ & 14 & 0 & $\mathbf{1 4}$ \\
\hline & $\mathbf{1}$ & 2 & 70 & 72 \\
\hline & Total & 16 & 70 & $\mathbf{8 6}$ \\
\hline
\end{tabular}

\begin{tabular}{|c|c|c|c|c|c|c|c|c|c|}
\hline & & \multicolumn{2}{|c|}{ PCR Test } & & & & \multicolumn{2}{|c|}{ LAMP_QiaAmp } & \\
\hline & Count & $\mathbf{0}$ & 1 & Total & & Count & $\mathbf{0}$ & 1 & Total \\
\hline \multirow{3}{*}{$\begin{array}{l}\text { LAMP } \\
\text { PURE }\end{array}$} & $\mathbf{0}$ & 5 & 5 & 10 & \multirow{2}{*}{$\begin{array}{r}\text { LAMP } \\
\text { PURE }\end{array}$} & $\mathbf{0}$ & 5 & 5 & 10 \\
\hline & 1 & 7 & 69 & 76 & & 1 & 0 & 76 & 76 \\
\hline & Total & 12 & 74 & 86 & & Total & 5 & 81 & 86 \\
\hline
\end{tabular}

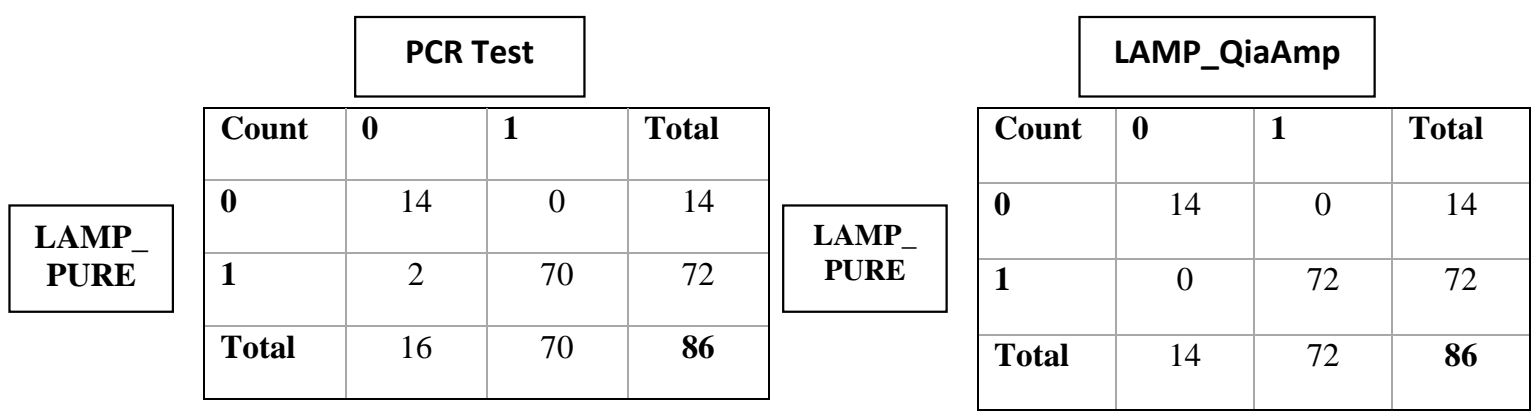


